\title{
AGE AS A FACTOR IN THE COMPLICATIONS RATES AFTER REMOVAL OF IMPACTED MANDIBULAR THIRD MOLARS: A REVIEW OF LITERATURE
}

\author{
Samir Mansuri'1, Abdul Mujeb Adbulkayum²
}

\section{HOW TO CITE THIS ARTICLE:}

Samir Mansuri, Abdul Mujeb Adbulkayum. "Age as a factor in the complications rates after removal of impacted mandibular third molars: a review of literature". Journal of Evolution of Medical and Dental Sciences 2013; Vol. 2, Issue 41, October 14; Page: 7994-8001

ABSTRACT: PURPOSE: The purpose of the study was to estimate the frequency of complications after mandibular third molar surgery, with age as the primary risk factor. PATIENTS AND METHODS: Review of literatures were selected and It was analyzed from last 25 years publications with a pubmed search using the following key words such as : impacted third molar, age, wisdom tooth, age and post operative complications ,age and inflammatory tissue reaction, mandibular third molar surgery, tooth extraction and age, wisdom tooth. Additionally, hand searching of key texts, references, and reviews relevant to the field were performed. RESULTS: The effect of age on post operative complications after third molar surgery was combined with other factors such as tooth, operating and clinical factors. Studies reviewed have shown that no specific age demonstrate increase morbidity. Pain, swelling and trismus were most common complications associated with increase age. CONCLUSIONS: The results of these analyses suggest that increased age appears to be associated with a higher complication rate for mandibular third molar extractions.

KEY WORD: Mandibular third molar; Age; Inflammatory complications;

INTRODUCTION: The extraction of the impacted mandibular third molar is a common oral surgical procedure $^{1}$ and often leading to complications, which are distressing to the patients ${ }^{2}$. Pain, trismus and swelling are the most common complications reported $(3,4)$ and they are thought to arise from inflammatory response. The adverse effects of the third molar surgery on the quality of life have been reported to show three-fold increase in patients who experience pain, swelling and trismus alone or in combination, compared to those who were asymptomatic 4 . Thus clinicians have emphasized the necessity for better pain, swelling and trismus control in patients who undergo third molar surgery 5 .

Factors affecting postoperative morbidity depend on patient factors, tooth related factors and operative factors ${ }^{6}$. Patient factors include age, sex, size or build, ethnic background, smoking, contraceptives and oral hygiene ${ }^{7}$. Tooth related factors include existing infection (pericoronitis), type of impaction, depth of impaction, relationship to inferior alveolar nerve, density of surrounding bone and associated pathology like cyst or neoplasm ${ }^{8}$. The operative factors include the use of drugs, type and extent of incision, wound closure technique, surgeons experience and duration of operation $(3,4)$.

A systematic review of the literature to identify relationship between the age and post operative complications following third molar surgery is widely variables. According to some studies indicate that older patients may result in more complications. The third molar surgery in increasing age appears to be a critical factor, which result in increasing morbidity. Conversely, there are no studies indicating a decrease in complications with increasing age. It also appears that recovery from complications is more prolonged, less predictable and less complete with increasing age. As such, 
many clinicians recommend removal of mandibular third molar in young patients. Some studies does not support the surgical morbidity with increase age ,so considering all these results ,this review of "Age as a factor in the complication rate after removal of impacted mandibular third molars" was carried out by pubmed search of last 25 years publications. This article is aimed at reviewing these modalities with particular emphasis on age group susceptible for more postoperative complications, along with finding an answer for, Does the age factor indicates the more post operative morbidity?

Literature review: A review of literatures was selected through pubmed electronic databases. The keywords used for the search were included in terms of: impacted third molar, age, wisdom tooth, age and post operative complication, age and inflammatory tissue reaction, mandibular third molar surgery, tooth extraction and age, wisdom tooth. Additionally, hand searching of key texts, references, and reviews relevant to the field were performed. The search was restricted to English language articles, published from 1985 to august 2013. Additionally, a manual search in the oral surgery journals and books was performed .Some papers that were not available or which lacked translation were included as references but their data were not included in our overall analysis

RESULTS: Age as a factor in the complication rate after removal of impacted mandibular third molars have been mentioned in scientific literatures as factors that influence the immediate postoperative reactions following third molar surgery. Consequently, clinician would profit from knowing the risk factors that are associated with postoperative complication following third molar surgery. This in turn will enable them to avoid patient subjecting to such factors, while carrying out lower third molar surgery.

Osborn TP et $\mathrm{al}^{9}$ evaluated the surgical and postsurgical problems in 9,574 patients of a wide range of ages during surgical extraction of 16,127, the result showed that removal of mandibular third molar teeth during the teenage decreased operative and postoperative morbidity.According to the Chiapasco $\mathrm{M}$ et $\mathrm{al}^{2}$ study indicated that the surrounding bone around the root of third molar in young patient is relatively soft and more resilient compared to older patients, if the bone is harder, necessitating more bone removal to separate tooth from bone, these leads to the more postoperative complication in older age patients.This was one of the reason for having more postoperative complications with increasing age.

Capuzzi $\mathrm{P}$ et al ${ }^{10}$ did a longitudinal prospective trial on 146 patients to evaluate which factors can have an effect on postoperative recovery after extraction of impacted third molars or wisdom teeth. The following factors were considered in their study: (1) age, (2) sex, (3) smoking habits, (4) use of the birth control pill, (5) previous history of pericoronitis, (6) degree of difficulty of the extraction, (7) expertise of the surgeon, (8) length of surgery, and (9) antibiotic prophylaxis. There were statistically significant differences were noted with respect to the pain in the context of age, sex-males noted more pain on the 1st and 3rd days $(\mathrm{p}<0.05)$ compared with females; while expertise of the surgeon--patients treated by surgeons with considerable or average expertise reported less pain on the first and third days $(\mathrm{p}<0.05)$ compared with patients treated by surgeons with little expertise ,irrespective of age and direct correlation was noted between age and pain $(\mathrm{p}<$ 0.05). 
Berge TI et al ${ }^{11}$ did predictor evaluation of postoperative morbidity after surgical removal of mandibular third molars. The effect of several pre- and post-operative variables on indicators of postoperative morbidity was assessed in 204 patients after unilateral mandibular third-molar surgery. The variables included gender, age, use of tobacco and alcohol, state of eruption, depth and angulation of the tooth, duration of the operation, pericoronitis, and time of day of surgery. Visual analogue scales were used for patient assessment of pain and swelling and for clinical assessment of swelling. Maximum pain was indicated $6 \mathrm{~h}$ postoperatively and maximum swelling the first postoperative evening. The results showed a mean reduction of mouth opening capacity (trismus) of $31 \%$ the 1 st postoperative day and the rate of postoperative alveolitis $1.9 \%$. The variation of the morbidity indicators was considerable in relation to the age of the patients.

In another study of Gaya MVO et $\mathrm{al}^{8}$ did an analysis on the influence of patient and surgical variables upon the postoperative complications normally associated with third molar extractions. They consider a series of 150 individuals subjected to third molar extraction: sex, age, and dimensions of neurotic personality trait and extroversion (based on the Eysenck Personality Inventory, EPI). The corresponding surgical intervention parameters were: duration, ostectomy degree, dental sectioning and number of sutures. Pain was scored on a visual analog scale (VAS) 0,8 , 24, 43 and 48 hours after surgery, while inflammation was rated by means of a verbal response scale (VRS) 48 hours after extraction. Multivariate analysis showed post extraction pain to be mainly related to patient age and the number of sutures on the day of the operation, and to swelling over the subsequent days. A less important relationship was observed with patient sex and the dimensions of neuroticism and extroversion. They noted older patients and those subjected to extractions involving a greater number of sutures refer the most intense pain. In turn, patients with increased intensity pain also present greater inflammation.

The study of Bui Chi $\mathrm{H}$ et $\mathrm{al}^{7}$ investigate the types, frequency, and risk factors for complications after third molar extractions in 583 patients ( $57.0 \%$ male) with a mean age of $26.4+$ /8.4 years . There retrospective cohort study consisted of patients who had 1 or more mandibular third molar removed between 1996 and 2001. They divided risk factors into demographic, general health, anatomic, and operative. Outcome variables were operative or inflammatory complications. They analyzed the data using descriptive, bivariate, and multivariate statistics. In their study overall complication rate was $4.6 \%$ and increasing age, a positive medical history, and the position of the mandibular third molar relative to the inferior alveolar nerve were associated with an increased risk for complications. While age, medical history, and mandibular anatomy cannot be altered directly, these factors may be modified indirectly, resulting in a potential decrease for postoperative complications.

According to the study of the Yuasa $\mathrm{H}$ et al ${ }^{12}$ relationship between preoperative findings and short-term outcome in third molar surgery (swelling and pain) differ depending on patients' characteristics (age and sex) and preoperative index of difficulty. They did analyses in 153 patients, who need surgical extractions of mandibular third molars in 140 patients. The median age was 27 years. They observed that 54 (35\%) of the 153 extractions were performed in male subjects and 99 $(65 \%)$ in female subjects. The amount of facial swelling varied depending on age and sex. Severe pain was associated with depth and preoperative index of difficulty. They consider that the shortterm outcomes of third molar operations. 
Haug RH et $\mathrm{al}^{13}$ carried out study to assess the frequency of complications of third molar surgery, both intraoperatively and postoperatively, specifically for patients 25 years of age or older. There prospective study evaluated on 3,760 patients, 25 years of age or older undergoes third molar surgery. The predictor variables were categorized as demographic (age, gender), American Society of Anesthesiologists classification, chronic conditions and medical risk factors, and preoperative description of third molars (present or absent, type of impaction, abnormalities or association with pathology). Outcome variables were intraoperative and postoperative complications, as well as quality of life issues (days of work missed or normal activity curtailed). Frequencies for data collected were tabulated. There result showed that the sample was provided by 63 surgeons, and was composed of 3,760 patients with 9,845 third molars who were 25 years of age or older, of which 8,333 third molars were removed. Alveolar osteitis was the most frequently encountered postoperative problem $(0.2 \%$ to $12.7 \%)$. Postoperative inferior alveolar nerve anesthesia/paresthesia occurred with a frequency of $1.1 \%$ to $1.7 \%$, while lingual nerve anesthesia/paresthesia was calculated as $0.3 \%$. All other complications also occurred with a frequency of less than 1\%.The findings of this study indicate that third molar surgery in patients 25 years of age or older is associated with minimal morbidity, a low incidence of postoperative complications, and minimal impact on the patient's quality of life graphic factors.

Adeyemo et al ${ }^{14}$ carried out prophylactic surgical extraction of impacted third molar in patients of 40 years of age at the University Teaching Hospital. This has been justified on the basis that the risk of surgical morbidity increases with increasing age among other reasons. In his study, he found a total of $6.3 \%$ of patients requiring third molar surgical extraction were 40 years or older. No intraoperative complications occurred in any of their patients. Only 3 patients $(9.7 \%)$ developed minor postoperative complications (infected socket, dry socket) which were reversible and of short duration) less than $7 \%$ of patients requiring surgical extraction of impacted third molars in his institution were 40 years and above. In addition, minor postoperative complications were seen in only 3 patients. His results does not support prophylactic surgical extraction of third molars based on the assumption that surgical morbidity increases with age. In the study of Gbotolorun $\mathrm{OM}$ et al ${ }^{15}$ related to the pattern of presentation of impacted Mandibular third molars, the indications for extraction and the post operative complications. The pattern of presentation of impacted mandibular third molars was similar to earlier reports in their study but the morbidity was however higher than the average value in the literature, it however does not seem to increase with increasing age.

In the recent literature of Adeyemo WL ${ }^{16}$, who did a study on 506 patients need prophylactic surgical extraction of impacted third molars on the bases that throughout the world justified on the presumption that the risk of surgical morbidity increases with increasing age, among other reasons. They analyze and compare surgical morbidity associated with third-molar extractions in young and aging populations who underwent the surgical extraction of impacted third molars between April 2001 and June 2006. A total of 506 patients had surgical extractions of impacted third molars under local anaesthesia during that period of their study. Of these, 470 (92.9 percent) patients were below the age of 40 years (Group A) and 36 (7.1 percent) patients were 40 years of age and older (Group B). 1, postoperative complications were reported in 70 (13.8 percent) patients. Of these 70 patients, 65 (92.9 percent) were from Group A and 5 (7.1 percent) were from Group B, and their complications included infected socket, dry socket, paraesthesia, and buccal space abscess. They 
observed that no significant difference in post-operative complications following surgical removal of mandibular third molars was found between patients 40 years old and greater and those below age 40. Prophylactic surgical extraction of impacted mandibular third molars, based on the assumption that surgical morbidity increases with age, may not be justifiable. Age does not predispose patients who had surgical extraction of mandibular third molars above 40 years of age to any additional surgical complications when compared to patients below the age of 40 years receiving comparable treatment.

Phillips $\mathrm{C}$ et $\mathrm{al}^{17}$ assessed the effects of age and sex on quality of life recovery after thirdmolar surgery in 958 patients. Healthy subjects scheduled for removal of third molars were recruited at multiple sites in his study. Each patient was given a condition-specific instrument to be completed each post surgery day for 14 days. They assess lifestyle and oral-function recovery by using a 5-point Likert-type scale. They defined recovery as the number of days until the patient reported no or little trouble. For each quality-of-life item, a Cox regression analysis was performed to assess the effects of age and sex on recovery after controlling for surgical-procedure variables. Except for ability to open the mouth, recovery for all quality-of-life items for those 21 years or older significantly $(\mathrm{P}<0.02)$ lagged behind recovery for younger subjects. Recovery for female subjects was significantly longer than for male subjects for all outcomes $(\mathrm{P}<0.01)$.Patients older than 21 and those who are female should be informed before removal of all 4 third molars that their oral function, lifestyle, and pain recovery will be prolonged compared with those who are younger and male.

Bello SA et al ${ }^{18}$ studied 120 patients with an age range of $19-42$ years showed that increasing operating time and advancing age are associated with more postoperative morbidity, also its related to impaction types. Pogrel $\mathrm{MR}^{19}$ summarizes the literature that addresses the following question: "Among patients undergoing third molar removal, patients who are younger eg, <25 years when compared with older patients, have a decreased risk for postoperative complications and more rapid recovery?" There studies indicate that as one becomes older, third molars become more difficult to remove, may take longer to remove, and may result in an increased risk for complications associated with removal.de Santana-Santos T et al $(20,23)$ investigate prediction of postoperative complications following third molar surgery based on preoperative variables involving 80 patients who required 160 surgical extractions of impacted mandibular third molars. Median age was 22.46 years in their study. Short-term outcomes of third molar operations (swelling, trismus and pain) differ depending on the patients' characteristics (age, gender and body mass index). Moreover, surgery characteristics such as operating time and tooth sectioning were also associated with postoperative variables in older age patients.

In the recent descriptive cross-sectional study of Obimakinde et al(21,22) on role of patients' demographic characteristics and its spatial orientation in predicting operative difficulty of impacted mandibular third molar and to assess the risk indicators of operative difficulty of mandibular third molar surgery involving patients that presented for wisdom tooth extraction. The correlation between patients' factors such as age, sex, weight, height, BMI, radiographic spatial relationship of the impacted tooth and operation time was determined with Spearman's rank correlation coefficient. Linear regression analysis of patients' age and angulation of mandibular third molar showed that both contribute $44.8 \%$ risk of increased operation time (regression coefficient $=0.448$ ), with mandibular third molar angulation contributing more significantly to increase in operation 
time $(\mathrm{p}=0.001)$ than increasing age of the patient $(\mathrm{p}=0.005)$. Findings from this study have shown that increasing age of the patient and the angulation of mandibular third molar impaction increases the risk of operative difficulty and post operative complications of the impacted significantly.

CONCLUSION: This article has presented the different results of different studies. The reviewed showed that increasing age of the patient is one of the factor, which affect the post operative complications on mandibular third molar impactions along with other operative and patient's factors. The age group of 25 to 30 years appears in many studies to be a critical time after which complications increase more rapidly but some of the studies does not support this evidence. It also appears that recoveries from the complications are more prolonged and less predictable and less complete with increasing age. Older patient likely to have more complications following third molar surgery mainly pain, swelling and trismus. Further mega trail studies will help to elucidate the true nature and magnitude of the association.

\section{BIBLIOGRAPHY:}

1. Ruta DA, Bissias E, Ogston S, Ogden GR. Assessing health outcomes after extraction of third molars: the postoperative symptoms severity (PoSSe) scale. Br J Oral Maxillofac Surg 2000, 38:480-487.

2. Chiapasco M, De Cicco L, Marroneh K. Side effects and complications associated with third molar surgery. Oral Surg Oral Med Oral Pathol 1993, 76:412-420.

3. Lopes V, Mumenya R, Feinmann C, Harris M. Third molar surgery. An audit of the indications for surgery, post operative complaints and patient satisfaction. Br J Oral Maxillofac Surg 1995, 33:33-35.

4. Garcia GA, Sampedro FH, Rey JH, Torreira MG. Trismus and pain after removal of impacted lower third molars Oral Maxillofac Surg 1997, 55:1223-1226.

5. Schultze-mosgau S, Schmelzeisen JC, Frolich JC, Schmele H. Use of ibuprofen and methylprednisolone for the prevention of pain and swelling after removal of impacted third molars. J Oral Maxillofac Surg 1995, 53:2-7.

6. Chiapasco M, De Cicco L, Marroneh K. Side effects and complication associated with third molar surgery. Oral Surg Oral Med Oral Pathol 1993,76:412-420

7. Bui Chi H, Seldin EB, Dodson TB. Types, frequencies and risk factors for complications after third molar extraction. J Oral Maxillofac Surg 2003, 61:1379-1389.

8. Gaya MVO, Capilla MV, Mateos RG. Relation of patient and surgical variables to postoperative pain and inflammation in the extraction of third molars. Medicinal Oral 2002, 7:360-369.

9. Osborn TP, Frederickson G Jr, Small IA, Torgerson TS. A prospective study of complications related to mandibular third molar surgery. J Oral Maxillofac Surg. 1985 Oct; 43(10):767-9.

10. Capuzzi P, Montebugnoli L, Vaccaro MA. Extraction of impacted third molars. A longitudinal prospective study on factors that affect postoperative recovery. Oral Surg Oral Med Oral Pathol. 1994; 77:341-3.

11. Berge TI, Boe OE. Predictor evaluation of postoperative morbidity after surgical removal of mandibular third molars. Acta Odontol Scand. 1994; 52(3):162-9. 
12. Yuasa H,Sugiura M: Clinical postoperative findings after removal of impacted mandibular third molars. Prediction of postoperative facial swelling and pain based on preoperative variables. Br J Oral Maxillofac Surg. 2004 Jun; 42(3):209-14.

13. Haug RH, Perrott DH, Gonzalez ML, Talwar RM. The American Association of Oral and Maxillofacial Surgeons Age-Related Third Molar Study. J Oral Maxillofac Surg. 2005 Aug; 63(8):1106-14.

14. Adeyemo WL, Ogunlewe MO, Ladeinde AL, Abib GT, Gbotolorun OM, Olojede OC, Hassan OO. Prevalence and surgical morbidity of impacted mandibular third molar removal in the aging population: a retrospective study at the Lagos University Teaching Hospital. Afr J Med Sci. 2006 Dec; 35(4):479-83

15. Gbotolorun OM, Arotiba GT, Ladeinde AL. Assessment of factors associated with surgical difficulty in impacted mandibular third molar extraction. J Oral Maxillofac Surg 2007, 65:1977-1983.

16. Adeyemo WL, Ogunlewe MO, Ladeinde AL, Hassan O0, Taiwo OA. A comparative study of surgical morbidity associated with mandibular third-molar surgery in young and aging populations. J Contemp Dent Pract. 2010 Jul 1;11(4):E001-8.

17. Phillips C, Gelesko S, Proffit WR, White RP Jr. Recovery after third-molar surgery: the effects of age and sex. Am J Orthod Dentofacial Orthop. 2010 Dec; 138(6):700.e1-8; discussion 7001. doi: 10.1016/j.ajodo.2010.06.013.

18. Bello SA, Adeyemo WL, Bamgbose BO, Obi EV, Adeyinka AA. Effect of age, impaction types and operative time on inflammatory tissue reactions following lower third molar surgery. Head Face Med. 2011 Apr 28; 7:8. doi: 10.1186/1746-160X-7-8.

19. Pogrel MA. What is the effect of timing of removal on the incidence and severity of complications? J Oral Maxillofac Surg. 2012 Sep;70(9 Suppl 1):S37-40. doi: 10.1016/j.joms.2012.04.028. Epub 2012 Jun 16.

20. de Santana-Santos T, de Souza-Santos aA, Martins-Filho PR, da Silva LC, de Oliveira E Silva ED, Gomes AC. Prediction of postoperative facial swelling, pain and trismus following third molar surgery based on preoperative variables. Med Oral Pathol Oral Cir Bucal. 2013 Jan 1; 18(1):e65-70.

21. Obimakinde O, Okoje V, Ijarogbe OA, Obimakinde A. Role of patients' demographic characteristics and spatial orientation in predicting operative difficulty of impacted mandibular third molar. Ann Med Health Sci Res. 2013 Jan; 3(1):81-4. doi: 10.4103/21419248.109512.

22. Fábio Wildson Gurgel Costa'; Erick Helton Lima FonteneleII; Tácio Pinheiro BezerraIII; Thyciana Rodrigues Ribeiro ${ }^{\mathrm{IV}}$; Bárbara Gressy Duarte Souza Carneirov; Eduardo Costa Studart Soares ${ }^{V}$. Acta Cir. Bras. vol.28 no.3 São Paulo Mar. 2013

23. de Boer M, Raghoebar GM, Stegenga B, Schoen PJ, Boering G: Complications after mandibular third molar extraction. Quitessence Int 1995, 26:779-784. 


\section{REVIEW ARTICLE}

\section{AUTHORS:}

1. Samir Mansuri

2. Abdul Mujeb Adbulkayum

\section{PARTICULARS OF CONTRIBUTORS}

1. Assistant Professor, Department of Oral Surgery, College of Dentistry, Taibah University, Madinah, KSA.

2. Associate Professor, Department of Oral Surgery, College of Dentistry, Taibah University, Madinah, KSA.

\section{NAME ADDRESS EMAIL ID OF THE} CORRESPONDING AUTHOR:

Dr. Samir Mansuri,

4/Farrukh Park Hill, 24/a Muslim Society, Navarangpura, Ahmedabad,

Gujarat, India - 380009.

Email - samirmansuri78@gmail.com

Date of Submission: 23/09/2013.

Date of Peer Review: 26/09/2013.

Date of Acceptance: 07/10/2013.

Date of Publishing: 11/10/2013 